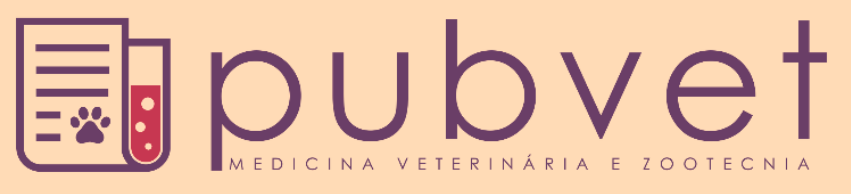

https://doi.org/10.31533/pubvet.v14n8a625.1-8

\title{
Detecção de anticorpos anti-Neospora caninum em bovinos leiteiros no município de Tiros, Minas Gerais
}

\author{
Lorena Aparecida de Bessa $^{1 *} \bullet$, Adriana Cristina Dias ${ }^{2} \bullet$, Abel da Silva Cruvinel $^{3 \bullet}$, Andresa \\ dos Santos $\operatorname{Veras}^{4}{ }^{\circ}$ Renata Lima de Miranda ${ }^{5}$ Nádia Grandi Bombonato $^{6}{ }^{\circ}$ Jacqueline \\ Ribeiro de Castro $^{70}$
}

${ }^{I}$ Graduanda em Medicina Veterinária, Centro Universitário de Patos de Minas - UNIPAM - MG, Brasil.

${ }^{2}$ Graduada em Ciências Biológicas, Centro Universitário de Patos de Minas - UNIPAM - MG, Brasil.

${ }^{3}$ Graduado em Engenharia Ambiental e Sanitária, Centro Universitário de Patos de Minas - UNIPAM - MG, Brasil.

${ }^{4}$ Graduanda em Medicina Veterinária, Faculdade Presidente Antônio Carlos - UNIPAC-MG, Brasil.

${ }^{5}$ Dra. do Programa de Pós-graduação em Imunologia e Parasitologia Aplicada-PIPPA-Universidade Federal de Uberlândia-UFU

${ }^{6}$ Docente em Medicina Veterinária, Centro Universitário de Patos de Minas - UNIPAM - MG, Brasil.

${ }^{7}$ Docente em Medicina Veterinária, Centro Universitário do Triângulo - UNITRI-MG, Brasil.

*Autor para correspondência: E-mail: jack_ufu@yahoo.com.br

Resumo. A neosporose é considerada uma das principais doenças causadoras de aborto na bovinocultura leiteira mundial. O agente etiológico é o Neospora caninum e pode causar distúrbios reprodutivos e neurológicos. Objetivou-se detectar anticorpos anti-Neospora caninum em fêmeas bovinas, no município Tiros, MG, bem como, estabelecer os possíveis fatores de risco envolvidos. Foram coletadas 100 amostras de soro sanguíneo de fêmeas bovinas, provenientes de 20 propriedades rurais distintas com diagnóstico fundamentado na sorologia por Enzyme-Linked Immunosorbent Assay (ELISA). Realizou-se análise estatística descritiva (frequências absoluta e relativa) e determinação de fatores de risco pelo teste não paramétrico Odds Ratio para duas amostras independentes, considerando um nível de significância de 5\%. A ocorrência detectada foi de 36\% (36/100). O fator de risco identificado foi ausência de assistência do médico veterinário $(\mathrm{P}<0,0451)$. Todas as propriedades $(100 \%, 20 / 20)$ avaliadas apresentavam histórico recente de alterações reprodutivas, como aborto, repetição de cio e/ou retenção de anexos fetais, com isso, fazem-se necessários estudos epidemiológicos que visem identificar os possíveis agentes etiológicos envolvidos para minimizar possíveis impactos econômicos, bem como, a atuação permanente e vigorosa do médico veterinário nas propriedades rurais do município.

Palavras chave: aborto, neosporose, ocorrência

\section{Detection of anti-Neospora caninum antibodies in dairy cattle in municipality Tiros, Minas Gerais}

Abstract. Neosporosis is considered one of the main diseases causing abortion in dairy farming worldwide. Neospora caninum is identified as a causal of reproductive problems and neurological disorders. The goal was to detect anti-Neospora caninum antibodies in cow, in the municipality of Tiros, MG, besides establish the possible risk factors involved. A total of 100 serum samples were collected from cow in 20 different rural properties with diagnosis based on serology by Enzyme-Linked Immunosorbent Assay (ELISA). Descriptive statistical analysis (absolute and relative frequencies) and determination of risk factors by the non-parametric Odds Ratio test for two independent samples was performed, considering a significance level of 5\%. The detected occurrence was 36\% (36/100). The risk factor identified was the lack of assistance from the veterinarian $(\mathrm{P}<0.0451)$. All properties $(100 \%, 20 / 20)$ evaluated had a recent history of reproductive changes, such as 
abortion, repetition of heat and / or retention of fetal attachments, therefore, epidemiological studies are needed to identify the possible etiological agents involved to minimize possible economic impacts, as well as the permanent and vigorous performance of the veterinarian in the rural properties of the municipality

Keywords: abortion, neosporosis, occurrence

\section{Detección de anticuerpos anti-Neospora caninum en ganado lechero en el municipio de Tiros, $M G$}

Resumen. La neosporosis se considera una de las principales enfermedades que causan el aborto en la producción lechera en todo el mundo. El agente etiológico es Neospora caninum y puede causar trastornos reproductivos y neurológicos. El objetivo fue detectar anticuerpos anti-Neospora caninum en hembras bovinas, en el municipio de Tiros, MG, así como establecer los posibles factores de riesgo involucrados. Se recogieron 100 muestras de suero sanguíneo de hembras bovinas, de 20 propiedades rurales diferentes con diagnóstico basado en serología mediante el ensayo de inmuno absorción enzimática (ELISA). Se realizó un análisis estadístico descriptivo (frecuencias absolutas y relativas) y la determinación de factores de riesgo mediante la prueba no paramétrica de Odds Ratio para dos muestras independientes, considerando un nivel de significancia del 5\%. La aparición detectada fue del 36\% (36/100). El factor de riesgo identificado fue la falta de asistencia del veterinario $(\mathrm{P}<0,0451)$. Todas las propiedades evaluadas $(100 \%, 20 / 20)$ tenían un historial reciente de cambios reproductivos, como el aborto, la repetición del calor y / o la retención de los accesorios fetales, por lo tanto, se necesitan estudios epidemiológicos para identificar los posibles agentes etiológicos involucrados para minimizar los posibles impactos económicos, así como el desempeño permanente y vigoroso del veterinario en las propiedades rurales del municipio.

Palabras clave: aborto, neosporosis, casuística

\section{Introdução}

A neosporose é causada pelo protozoário Neospora caninum ( $N$. caninum) que foi identificado pela primeira vez 1984 em ambiente rural (Megid et al., 2016). Relevante na pecuária de leite por causar distúrbios reprodutivos, com intervalos de cio irregulares e abortos, geralmente registrados entre o quinto e sexto mês de gestação, além de manifestações neurológicas, principalmente em bezerros ( $\underline{\text { Bruhn }}$ et al., 2012; Megid et al., 2016).

Os hospedeiros intermediários dessa coccidiose são: bovinos, ovinos, caprinos, equinos, felinos, cervídeos e bubalinos (Basso et al., 2010). Como hospedeiros definitivos destacam-se os canídeos, com cão doméstico apresentando papel determinante no ciclo dessa parasitose no ambiente rural (Megid et al., 2016).

O N. caninum pode ser transmitido de forma horizontal e vertical. Na transmissão horizontal, os hospedeiros intermediários adquirem a neosporose por meio da ingestão de oocistos esporulados na água ou alimentos, que são excretados nas fezes do hospedeiro definitivo. Já os hospedeiros definitivos se infectam ingerindo tecidos ou órgãos com cistos dos hospedeiros intermediários, como, os anexos placentários de vacas infectadas. Na transmissão vertical, a fêmea gestante infecta seu feto via transplacentária, podendo manter o parasita no rebanho durante gerações, por meio da transmissão vertical, não apresentando manifestações clínicas aparentes e se mantendo como portadores e relevantes disseminadores do patógeno (Reichel et al., 2013).

Por ser uma doença de caráter de polimorfismo clínico, e na maior parte dos casos cursar de forma inaparente, estima-se que no Brasil, os prejuízos econômicos causados pela neosporose sejam superiores à brucelose e leptospirose, que também são doenças abortivas (Vianna et al., 2008). Os métodos de diagnóstico mais utilizados na rotina são os métodos indiretos, que verificam a presença de anticorpos anti- $N$. caninum no soro dos hospedeiros, sendo comumente empregados o teste de imunofluorescência 
indireta e o teste do ensaio imuno enzimático Enzyme-Linked Immunosorbent Assay (ELISA) (Carvalho et al., 2014).

Não existe vacinação eficaz que evite os abortos nos bovinos ou a eliminação de oocistos pelos cães (Reichel et al., 2013). O controle deve se basear na interrupção do ciclo biológico do parasito. Portanto deve-se impedir o acesso de cães às fontes de alimento de ruminantes e também, é essencial a remoção de anexos placentários, fetos abortados e animais mortos, a fim de se evitar a ingestão de restos placentários pelos cães (Teixeira et al., 2010).

Mediante a relevância da neosporose na bovinocultura leiteira, o presente estudo visou detectar a presença de anticorpos anti- $N$. caninum em fêmeas bovinas no município de Tiros, MG, bem como, identificar os possíveis fatores de risco envolvido na ocorrência dessa doença.

\section{Material e métodos}

Este estudo foi conduzido conforme os princípios éticos de experimentação animal e mediante a submissão e aprovação do Comitê de Ética no Uso de Animais (CEUA) do Centro Universitário de Patos de Minas (UNIPAM), sob o número do protocolo 04/19 e após prévia autorização dos proprietários.

\section{Local de estudo}

Tiros é um município brasileiro do estado de Minas Gerais localizado na Mesorregião do Triângulo Mineiro e Alto Paranaíba e na Microrregião de Patos de Minas. O município tem como principal atividade a pecuária de leite, alcançando em 2014 o vigésimo segundo lugar entre os municípios com maior produção de leite, produzindo um total de 80.512 litros de leite por ano (ANUALPEC, 2019).

\section{Delineamento do estudo e cálculo amostral}

Foi realizado um estudo observacional transversal prospectivo, no período de abril a agosto de 2019. A amostragem foi definida utilizando-se o método de georreferenciamento, com a determinação exata (latitude e longitude) das propriedades selecionadas, por meio de um Sistema de Posicionamento Global (GPS e-Trex 10 Garmin $^{\circledR}$ ) para confecção de um mapa com a distribuição dos animais reagentes conforme a área.

A região estudada foi estratificada e avaliada de acordo com os recursos disponíveis, como presença de rios e foram rotuladas quanto à compatibilidade para o desenvolvimento da bovinocultura leiteira. As áreas que apresentavam características mais propícias, consequentemente ficaram com maior parte da amostragem. As propriedades foram selecionadas por de sorteio aleatório de forma que a amostra fosse representativa do município.

O rebanho de bovinos no município de Tiros é de cerca 80310 cabeças, sendo 21415 cabeças acima de 24 meses, independente da raça e sexo, distribuído em 1.110 propriedades destinadas à produção de leite e corte. Para se determinar o tamanho amostral considerou-se frequência esperada de $18,4 \%$ bovinos reagentes ao $N$. caninum, conforme estudo realizado em bovinos leiteiros, no município de Uberlândia, MG (Nasciutti et al., 2018). Foi estabelecido um nível de confiança de $95 \%$ e com erro estimado de 5\% $(\alpha=0,05)$, totalizando uma amostra representativa de 100 animais.

No município de Tiros atualmente no perímetro rural existem cerca de 1110 fazendas cadastradas no Instituto Mineiro de Agropecuária (IMA) sendo essas, destinadas à bovinocultura de leite e corte. As propriedades foram selecionadas aleatoriamente, de acordo com o zoneamento disponibilizado pela prefeitura. Selecionaram-se cinco animais por fazenda, perfazendo 20 propriedades amostradas.

\section{Caracterização da população e critérios de seleção}

Foram incluídas no estudo 100 fêmeas adultas da espécie Bos taurus, independentemente da idade, do padrão racial e do sistema de produção destinadas à produção leiteira, exclusivamente pertencente à propriedade do município de Tiros, Minas Gerais. 
Propriedades que não possuíam registros dos animais, quanto aos fatores de risco estudados, como histórico reprodutivo, identificação dos animais e desautorização do responsável durante o procedimento de colheita foi retirada do estudo e substituída, em busca da manutenção do $\mathrm{n}$ amostral calculado.

\section{Questionário epidemiológico}

Foi realizado um inquérito epidemiológico com aplicação de um questionário, a fim de se avaliar fatores de risco inerentes à ocorrência da doença. As variáveis consideradas como possíveis fatores de risco para a neosporose relacionaram-se as características individuais inerentes aos animais e de cada propriedade.

Os fatores analisados foram idade, raça, sistema de produção (extensivo, semi-intensivo ou intensivo), tipo de ordenha (manual ou mecânica), se ocorre compra frequente de animais, histórico de problema reprodutivo (retenção de placenta, repetição de cio e aborto); presença de aborto (sim, não, raramente); época do aborto (terço inicial, médio ou final da gestação); manejo dos fetos abortados e destino das vacas que abortaram; presença de assistência veterinária, introdução frequente de novo animais no rebanho; histórico de vacinação e vermifugação dos animais.

\section{Coleta de material}

A coleta de sangue foi realizada com o animal em estação, contido fisicamente em um brete, por meio da punção da veia coccígea na cauda, utilizando-se seringas descartáveis de $10 \mathrm{~mL}$ e agulhas $25 \mathrm{x}$ 8 estéreis, após antissepsia com álcool em tubos a vácuo sem anticoagulante, devidamente identificados. As amostras foram adequadamente mantidas refrigeradas após a coleta, em um compartimento isotérmico com gelo reciclável, e posteriormente encaminhadas ao Laboratório de Patologia Clínica do Centro Clínico Veterinário, do UNIPAM. Após as amostras foram centrifugadas a $3000 \mathrm{rpm}$ por cinco minutos para extração do soro, aliquotadas em tubos de polietileno de fundo cônico e armazenadas -20 ${ }^{\circ} \mathrm{C}$ para serem enviadas ao laboratório para análise.

\section{Teste sorológico}

$\mathrm{O}$ exame para determinação de anticorpos anti-Neospora caninum foi realizado em laboratório comercial particular consolidado no mercado, Tecsa ${ }^{\circledR}$, em Belo Horizonte, Minas Gerais. Utilizou-se o método ELISA previamente validado para a determinação de neosporose para a espécie bovina (Guedes et al., 2008), o qual, utilizou anticorpos específicos para $N$. caninum, com a utilização de amostras em duplicata.

\section{Análise estatística}

Para cálculo da frequência foi dividido o número de animais soro reagentes pelo número de animais amostrados, utilizando-se análise estatística descritiva por meio de frequências absoluta e relativa. $\mathrm{O}$ programa utilizado para a análise estatística foi o Graphpad versão 5.0 para Windows (San Diego, California, USA), utilizando-se um teste não paramétrico Odds Ratio para duas amostras independentes para determinação de fatores de risco, considerando um nível de significância de 5\%.

\section{Resultados}

Determinou-se uma ocorrência de 36\% (36/100) de fêmeas bovinas que apresentaram anticorpos anti-N. caninum na região de Tiros, Minas Gerais.

A ocorrência de anticorpos anti- $N$. caninum nesse percentual relevante aponta que o agente pode estar presente em muitas propriedades da região estudada. Observou-se que 85\% (17/20) das fazendas avaliadas apresentaram pelo menos um animal reagente. Fato esse que alerta a região, uma vez que, a neosporose pode ser a causa de distúrbios reprodutivos presentes no rebanho da região e pode estar sendo subestimada, por cursar com parte significante de animais assintomáticos, embora, estejam cronicamente afetados (Vianna et al., 2008). A distribuição dos bovinos soro reagentes no município de Tiros encontra-se detalhada na figura 1. 


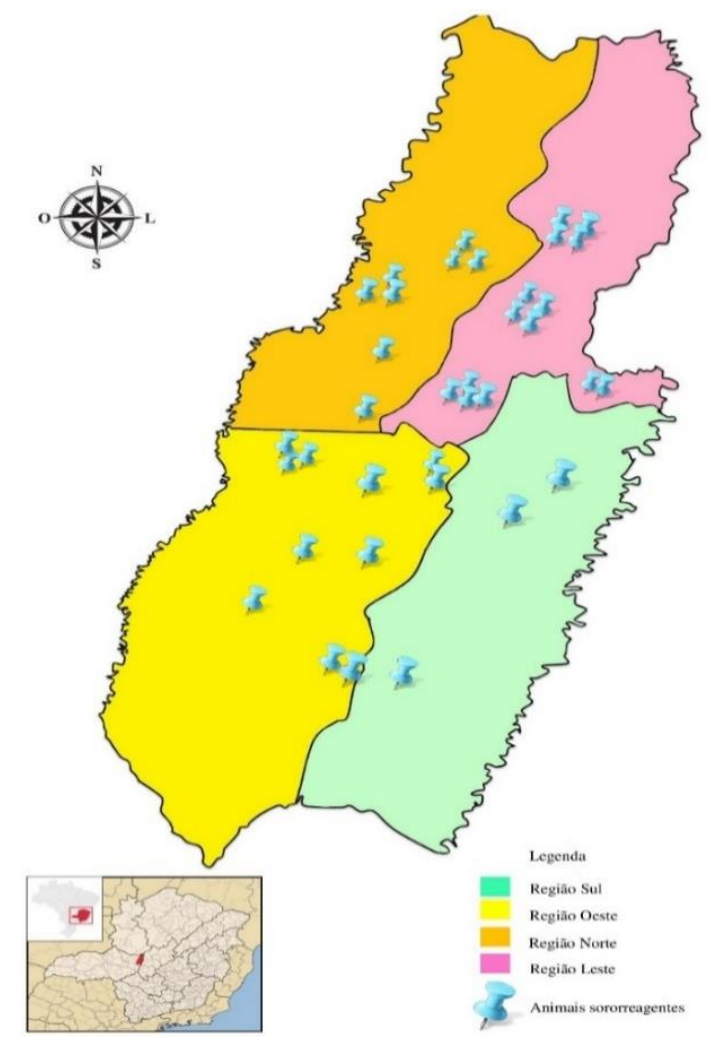

Figura 1. Distribuição dos 36 animais soro reagentes a Neospora caninum em regiões do município de Tiros, MG. *Fonte: Dados da pesquisa, 2019. *A escala utilizada foi de 1: 100.000

Detectou-se um maior percentual de animais regentes $(61,1 \%$; 22/36) nas regiões Norte e Leste do município (Figura1). Essa maior ocorrência pode ser justificada pelo fato de que a maioria das propriedades dessa região eram menos tecnificadas. A maioria dessas adotava o sistema de criação extensivo ou semi-intensivo, com aquisição frequente de animais, e algumas não tinham assistência do médico veterinário.

A região sul do município apresentou o menor número de animais soro reagentes $(8,3 \% ; 3 / 36)$. Esse número inferior pode ser devido a maior concentração de propriedades de sistema intensivo nessa área, nas quais, o controle sanitário dos animais é mais rígido, com assistência frequente do médico veterinário, e uma menor rotatividade de animais nas propriedades, dificultando assim, a disseminação do agente.

Comparando os resultados os obtidos com outros estudos que também utilizaram o método ELISA para a detecção dos anticorpos, os valores foram semelhantes aos apresentados por Dittrich et al. (2008), Justo et al. (2013) e Sartor et al. (2005) os quais encontraram uma ocorrência de 35,5\% (145/408), 33,0\% (423/1.263) e 37,6\%, respectivamente. Frequências inferiores foram encontradas por Nasciutti et al. (2018) que identificaram 18,4\% (136/740) de animais soro reagentes para o N. caninum e Langoni et al. (2013) de $24,0 \%$.

$\mathrm{O}$ aumento de animais soro reagentes pode estar relacionado à falta de conhecimento dos produtores rurais a respeito da Neosporose e seus métodos de profilaxia, levando a acreditar que essa doença esteja sendo subdiagnosticada nas propriedades. Este aumento também pode estar relacionado ao sistema de criação, pois, $85 \%$ das propriedades adotavam regime semi-intensivo ou extensivo, no qual os animais ficam na maior parte do tempo em piquetes a pasto, o que facilita acesso de cães as fontes de alimentação dos bovinos e também, aos anexos placentários e fetais. Outro fator que pode ter contribuído para esse aumento é o manejo inadequado dos fetos abortados. Como demonstrado (Tabela 1), 70,0\% das propriedades não faziam nenhum manejo de descarte com os fetos abortados, apesar de não ter sido um fator de risco relevante nesse estudo, esses fatores contribuem para a manutenção do coccídeo no 
ambiente, uma vez que, a ingestão de fetos abortados e anexos placentários contaminados é a principal fonte de infeção para os canídeos.

A assistência do médico veterinário demonstrou ser um fator de risco relevante $(\mathrm{P}=0,0451, \mathrm{OR}: 1,27$; IC: $0,13-7,09)$ na detecção de anticorpos anti- $N$. caninum. Resultado semelhante foi apresentado em um estudo feito por Silva et al. (2008). A ausência de assistência veterinária nas propriedades rurais implica diretamente no aumento dos animais soro reagentes, pois, sem a orientação profissional não são implementadas medidas efetivas de controle e profilaxia, ou a identificação de outras doenças e que podem causar distúrbios semelhantes à neosporose. Os fatores de risco avaliados encontram-se detalhados na tabela 1.

Tabela 1. Distribuição das fêmeas bovinas com anticorpos anti- $N$. caninum conforme os fatores de risco avaliados, no município de Tiros, MG em 2019.

\begin{tabular}{|c|c|c|c|c|c|c|}
\hline \multirow{2}{*}{ Variáveis } & \multicolumn{3}{|c|}{ Fêmeas } & \multirow{2}{*}{$O R^{*}$} & \multirow{2}{*}{ IC $95 \%$} & \multirow{2}{*}{$\mathrm{P}$} \\
\hline & Total & Reagentes & Frequência (\%) & & & \\
\hline \multicolumn{7}{|l|}{$\overline{\text { Idade }}$} \\
\hline$\leq 60$ meses & 50 & 16 & 32 & \multirow{2}{*}{0,7} & \multirow{2}{*}{$0,31-1,64$} & \multirow{2}{*}{0,5323} \\
\hline$>60$ meses & 50 & 20 & 40 & & & \\
\hline \multicolumn{7}{|l|}{ Raça } \\
\hline Cruzamento H+GIR & 60 & 21 & 35 & \multirow{2}{*}{0,7} & \multirow{2}{*}{$0,39-2,6$} & \multirow{2}{*}{0,8339} \\
\hline Com raça definida & 40 & 15 & 37,5 & & & \\
\hline \multicolumn{7}{|l|}{ Sistema de produção } \\
\hline Extensivo & 10 & 2 & 20 & \multirow{3}{*}{$0,22 * *$} & \multirow{3}{*}{$0,28-1,8$} & \multirow{3}{*}{0,2857} \\
\hline Semi-intensivo & 75 & 27 & 36 & & & \\
\hline Intensivo & 15 & 7 & 46,66 & & & \\
\hline \multicolumn{7}{|l|}{ Tipo ordenha } \\
\hline Manual & 5 & 1 & 20 & \multirow{2}{*}{0,42} & \multirow{2}{*}{$0,04-3,99$} & \multirow{2}{*}{0,6514} \\
\hline Mecânica & 95 & 35 & 36,84 & & & \\
\hline \multicolumn{7}{|l|}{ Evol. do rebanho*** } \\
\hline Sim & 75 & 27 & 36 & \multirow{2}{*}{1,00} & \multirow{2}{*}{$0,38-2,56$} & \multirow{2}{*}{1,0000} \\
\hline Não & 25 & 9 & 36 & & & \\
\hline \multicolumn{7}{|l|}{ Histórico de aborto } \\
\hline Raro & 20 & 6 & 30 & \multirow{2}{*}{1,4} & \multirow{2}{*}{$0,48-4,03$} & \multirow{2}{*}{0,6100} \\
\hline Frequente & 80 & 30 & 37,5 & & & \\
\hline \multicolumn{7}{|c|}{ Destino vacas abortam } \\
\hline Investigação aborto & 10 & 5 & 50 & \multirow{2}{*}{1,9} & $051-708$ & 04866 \\
\hline Descartadas & 90 & 31 & 34,44 & & (-) & 0,4000 \\
\hline Assistência veterinár & & & & & & \\
\hline Sim & 95 & 32 & 33,68 & 127 & 012700 & 00451 \\
\hline Não & 5 & 4 & 80 & 1,21 & $0,15-1,09$ & 0,0431 \\
\hline Manejo fetos abortac & & & & & & \\
\hline Permanecem no local & 70 & 28 & 40 & 182 & 071460 & 02501 \\
\hline Enterrados & 30 & 8 & 26,66 & $1,0 J$ & $0,11-4,09$ & $0,2 J 01$ \\
\hline
\end{tabular}

As variáveis idade, raça, repetição de cio, sistema de produção, tipo de ordenha, evolução do rebanho, histórico de aborto, destino dos fetos abortados e das vacas, não foram fatores de risco significativos no presente estudo. Resultado esse, que difere dos estudos apresentados por Lorenzett et al. (2016), Nasciutti et al. (2018) e Silva et al. (2008), os quais apontaram esses fatores como relevantes na ocorrência da neosporose bovina. Silva et al. (2008) relataram associação significativa com manuseio do feto $(\mathrm{P}<0,001)$; destino das vacas que abortaram $(\mathrm{P}=0,004)$ e com alguns fatores relacionados aos distúrbios reprodutivos como histórico de aborto $(\mathrm{P}=0,042)$ e época do aborto $(\mathrm{P}=0,014)$. Nasciutti et 
al. (2018) verificaram que a compra frequente de animais aumenta 3,8 vezes o risco de os animais adquirirem a neosporose, e que propriedades que tenham cem vacas com mais de 24 meses tiveram riscos três vezes maior de terem a infecção. Lorenzett et al. (2016) observaram que com a introdução de fêmeas primíparas na propriedade ocorre um aumento de 1,89 vezes do risco de terem animais positivos. Essa diferença nos fatores de risco em diferentes estudos pode ser explicada pela epidemiologia polimórfica envolvida no ciclo da neosporose em bovinos que dependem das características ambientais, individuais e do comportamento do agente em cada região estudada.

Os possíveis fatores de risco histórico de alterações reprodutivas, presença de cães e possível contato com canídeos silvestres, vacinação e vermifugação não foram consideradas na análise estatística desse estudo, uma vez que, não sofreram variabilidade, pois em todas as propriedades vacinavam e vermifugavam seus rebanhos na sua totalidade e possuíam contato direto e/ou indireto com canídeos.

Dos animais avaliados, cerca de 20,0\% apresentavam raro histórico de aborto e $80 \%$ das propriedades alegaram ter abortos frequentes. Cerca de $50 \%$ alegaram que os abortos acorreram no terço médio e final da gestação, enquanto que, $25 \%$ das propriedades avaliadas apontaram ter abortos frequentes no terço inicial e médio do período gestacional.

Além da neosporose, existem outras doenças de origem bacteriana (Brucelose e Leptospirose) e viral (Diarreia Viral Bovina e Rinotraqueite Infecciosa Bovina) que podem ocasionar perdas gestacionais. A principal manifestação clínica da neosporose é caracterizada pelo aborto entre o quinto e o sexto mês (terço médio) de gestação, o que pode variar de acordo com o momento da parasitemia da vaca, podendo ocorrer em qualquer momento da gestação (Teixeira et al., 2010).

Quando se trata de brucelose o aborto geralmente ocorre no terço final da gestação, e no primeiro parto após a infecção (Megid et al., 2016; Sola et al., 2014). O aborto na leptospirose pode ocorrer em qualquer fase gestacional, dependendo do momento em que o animal vai adquirir a infecção (Megid et al., 2016). A diarreia viral bovina é geralmente assintomática. Contudo, há cepas de alta virulência que, na infecção transplacentária pode causar morte embrionária e fetal causando aborto na maioria das vezes até o quinto mês de gestação (Fino et al., 2012). A rinotraqueíte infecciosa bovina também é uma doença de origem viral caracterizada por aborto, que geralmente acontece com seis a oito meses de gestação (Megid et al., 2016). O período em que ocorre o aborto na rinotraqueíte e na diarreia viral bovina (terço médio da gestação), se assemelham ao que é observado na neosporose (Megid et al., 2016).

Dessa forma, vale salientar a importância em se realizar o diagnóstico diferencial das doenças reprodutivas em bovinos que causam aborto, incluindo nessa triagem a neosporose, que se encontra difundida no território brasileiro (Bruhn et al., 2012; Lorenzett et al., 2016; Nasciutti et al., 2018) gerando impactos relevantes na bovinocultura nacional.

\section{Conclusão}

Detectou-se a presença de 36\% (36/100) fêmeas bovinas com anticorpos anti- N. caninum, no município de Tiros, MG. O principal fator de risco identificado foi a ausência de assistência do médico veterinário. Todas as propriedades avaliadas apresentavam histórico recente de alterações reprodutivas, como aborto, repetição de cio e/ou retenção de anexos fetais, fazem-se necessários estudos epidemiológicos que visem identificar os possíveis agentes etiológicos envolvidos para minimizar possíveis impactos econômicos, bem como, a atuação permanente e vigorosa do médico veterinário nas propriedades rurais do município.

\section{Referências bibliográficas}

ANUALPEC. (2019). Anuário da Pecuária Brasileira (20th ed., Vol. 1). Instituto FNP.

Basso, W., Schares, S., Minke, L., Bärwald, A., Maksimov, A., Peters, M., Schulze, C., Müller, M., Conraths, F. J., \& Schares, G. (2010). Microsatellite typing and avidity analysis suggest a common source of infection in herds with epidemic Neospora caninum-associated bovine abortion. Veterinary Parasitology, 173(1-2), 24-31. https://doi.org/10.1016/j.vetpar.2010.06.009

Bruhn, F. R. P., Teófilo, T. S., Guimarães, A. K. V., Lima, R. F., Andrade, G. S., \& Guimarães, A. M. (2012). Neosporose em ruminantes. PUBVET, 6, Art-1270. 
https://doi.org/10.22256/pubvet.v16n2.1276

Carvalho, R. P., Rabbers, A. S., Dutra, H. T., Silva, K. S., Batista, J. F., Lima, C. R. de O., \& Rabelo, R. E. (2014). Neosporose bovina-revisão de literatura. Revista Científica de Medicina Veterinária, 23(7), 1-23.

Dittrich, R. L., Machado Júniorr, P. C., Fridlund, N., Richartz, R. R., Ferreira., F. M., Patrício, L. F., \& Pieppe, M. (2008). Determinação e correlação de anticorpos anti-Neospora caninum em bovinos e cães do Paraná, Brasil. Revista Brasileira de Parasitologia Veterinária, 17(1), 191-195.

Fino, T. C. M., Melo, C. B., Ramos, A. F., \& Leite, R. C. (2012). Diarréia bovina a vírus (BVD)-uma breve revisão. Brazilian Journal of Veterinary Medicine, 34(2), 131-140.

Guedes, M. H. P., Guimarães, A. M., Rocha, C. M. B. M., \& Hirsch, C. (2008). Freqüência de anticorpos anti-Neospora caninum em vacas e fetos provenientes de municípios do sul de Minas Gerais. Revista Brasileira de Parasitologia Veterinária, 17(4), 189-194. https://doi.org/10.1590/s198429612008000400004

Justo, R. V., Manfio, J. B., Galhardo, J. A., Garcia, J. L., \& Campos, A. K. (2013). Inquérito soroepidemiológico sobre neosporose bovina no norte do estado de Mato Grosso, Brasil. Semina: Ciências Agrárias, 34(2), 3897-3902. https://doi.org/10.5433/1679-0359.2013v34n6supl2p3889

Langoni, H., SilvaA, A. V, Katagiri, S., Cagnini, F., \& Ribeiro, C. M. (2013). Avaliação sorológica para Neospora caninum em propriedades de bovinos leiteiros com alterações reprodutivas. Veterinária e Zootecnia, 20(1), 124-130.

Lorenzett, M. P., Lucca, N. J., Henker, L. C., Machado, G., Gomes, D. C., Mendes, R. E., Driemeier, D., \& Casagrande, R. A. (2016). Ocorrência de anticorpos anti-Neospora caninum em bovinos leiteiros no oeste do estado de Santa Catarina, Brasil. Brazilian Journal of Veterinary Medicine, 38(3), 243-249.

Megid, J., Ribeiro, M. G., \& Paes, A. C. (2016). Doenças infecciosas em animais de produção e de companhia. Roca.

Nasciutti, N. R., Oliveira, P. M., Barbosa, V. M., Headley, S. A., Garcia, F. G., Silva, M. V, Ferreira, F. B., Mineo, T. W. P., \& Saut, J. P. E. (2018). Soroprevalência e fatores de risco associados ao herpesvírus bovino tipo 1, vírus da diarréia viral bovina em vacas leiteiras mestiças não vacinadas e Neospora caninum no município de Uberlândia. Semina: Ciencias Agrarias, 39(4), 1585-1594. http://dx.doi.org/10.5433/1679-0359.2018v39n4p1585

Reichel, M. P., Alejandra Ayanegui-Alcérreca, M., Gondim, L. F. P., \& Ellis, J. T. (2013). What is the global economic impact of Neospora caninum in cattle - The billion dollar question. International Journal for Parasitology, 43(2), 133-142. https://doi.org/10.1016/j.ijpara.2012.10.022

Sartor, I. F., Garcia Filho, A., Vianna, L. C., Pituco, E. M., Dal Pai, V., \& Sartor, R. (2005). Ocorrência de anticorpos anti-Neospora caninum em bovinos leiteiros e de corte da região de Presidente Prudente, SP. Arquivos Do Instituto Biológico, 72(4), 413-418.

Silva, M. I. S., Almeida, M. Â. O., Mota, R. A., Pinheiro Júnior, J. W. P., \& Rabelo, S. S. A. (2008). Fatores de riscos associados à infecção por Neospora caninum em matrizes bovinas leiteiras em Pernambuco. Ciência Animal Brasileira, 9(2), 455-461.

Sola, M. C., Freitas, F. A., Sena, E. L. S., \& Mesquita, A. J. (2014). Brucelose bovina: revisão. Enciclopédia Biosfera, 10(18), 186-714.

Teixeira, W. C., Uzêda, R. S., Gondim, L. F. P., Silva, M. I. S., Pereira, H. M., Alves, L. C., \& Faustino, M. A. G. (2010). Prevalência de anticorpos anti-Neospora caninum (Apicomplexa: Sarcocystidae) em bovinos leiteiros de propriedades rurais em três microrregiões no estado do Maranhão. Pesquisa Veterinária Brasileira, 30(9), 729-734.

Vianna, L. C., Sartor, I. F., Pituco, E. M., Okuda, L. H., Camargo, C. N., \& Kronka, S. N. (2008). Incidence and transplacental transmission of Neospora caninum in primiparous females from Bos indicus slaughtered in Presidente Prudente, São Paulo, Brazil. Semina: Ciências Agrárias, 29(2), 387-392. https://doi.org/10.5433/1679-0359.2008v29n2p387

Recebido: 18 de março, 2020.

Aprovado: 16 de abril, 2020.

Disponível online: 16 de agosto, 2020.
Licenciamento: Este artigo é publicado na modalidade Acesso Aberto sob a licença Creative Commons Atribuição 4.0 (CC-BY 4.0), a qual permite uso irrestrito, distribuição, reprodução em qualquer meio, desde que o autor e a fonte sejam devidamente creditados. 